Slonaker, J. R. (1931a). Amer. F.Physiol. 96, 547.

Slonaker, J. R. (r93rb). Amer. F. Physiol. 97, 322.

Slonaker, J. R. (1931c). Amer. F. Physiol. 97, 573.

Slonaker, J. R. (193Id). Amer. F. Physiol. 97, 626

Slonaker, J. R. (r93re). Amer. F. Physiol. 98, 266.

Slonaker, J. R. (1935). Amer. F. Physiol. 1r3, 59.

Slonaker, J. R. (1938). Amer. F. Physiol. 123, 526.

Yudkin, J. (I944). Lancet, 247, 384 .

\title{
Nutritional status, maternal physique and reproductive efficiency
}

\section{By A. M. Thomson and W. Z. Billewicz, Obstetric Medicine Research Unit (Medical Research Council), University of Aberdeen}

Some time ago, the obstetricians in Aberdeen classified primigravidae, at their first attendance at an antenatal clinic, according to their general clinical appearance. Those who were in poor physical condition often had the appearance of being illnourished, though lesions indicative of specific deficiency states were almost never seen. In due course we correlated the clinical assessments with the subsequent obstetric histories. Table I gives some of the results; the rates of prematurity (birth weight $2500 \mathrm{~g}$ or less), Caesarean section and perinatal death were much higher among women originally thought to be in poor general condition than in those thought to be in good condition.

Table I. Incidence of obstetric abnormalities in Aberdeen primigravidae by maternal health and physique as assessed at the first antenatal examination. Twin pregnancies have been excluded

\begin{tabular}{|c|c|c|c|c|}
\hline & \multicolumn{4}{|c|}{ Health and physique } \\
\hline & Very good & Good & Fair & Poor; very poor \\
\hline Prematurity* $(\%)$ & $5 \cdot I$ & $6 \cdot 4$ & 10.4 & $12 \cdot I$ \\
\hline Caesarean section $(\%)$ & $2 \cdot 7$ & $3 \cdot 5$ & $4 \cdot 2$ & $5 \cdot 4$ \\
\hline Perinatal deaths & & & & \\
\hline per rooo births & $26 \cdot 9$ & $29 \cdot 2$ & $44 \cdot 8$ & 62.8 \\
\hline No, of subjects & 707 & 2088 & 1294 & 223 \\
\hline Percentage tall & & & & \\
\hline$(5 \mathrm{ft} 4$ in. or more $)$ & 42 & 29 & 18 & I3 \\
\hline $\begin{array}{l}\text { Percentage short } \\
\text { (under } 5 \mathrm{ft} \mathrm{x} \text { in.) }\end{array}$ & 10 & 20 & 30 & 48 \\
\hline
\end{tabular}

The lower part of Table I shows that women in poor condition were often shorter than those in good condition. A possible explanation is that many short women had been poorly nourished during growth, and became stunted as well as generally unhealthy adults. Conversely, tall women had mostly been well-nourished during growth, and became healthy adults who reached the full stature of which they were genetically capable. Some support for the hypothesis that many short individuals are stunted rather than genetically short was provided by Bernard (r952). He showed that in groups of short women and men antero-posterior flattening of the pelvic brim, resembling that found in the rachitic pelvis but less in degree, was common, 
whereas in tall groups pelvic distortion was uncommon. The undistorted, round pelvis is, of course, much better adapted to childbirth than the flat pelvis.

There is no doubt that women are, on average, taller in the upper socio-economic groups and shorter in the poorer groups. This association between socio-economic status and stature is remarkably delicate. Fig. I (Thomson, 1959) shows the percentage of short women (stature under $6 \mathrm{I}$ in.) according to (a) the occupations of their fathers, (b) their own occupations after leaving school, and (c) the occupations of their husbands. In each division and subdivision the proportion of short women increases as the occupational category falls from non-manual $(\mathrm{N})$, to skilled manual (S) and to unskilled manual (U). It is remarkable that adult stature-a characteristic

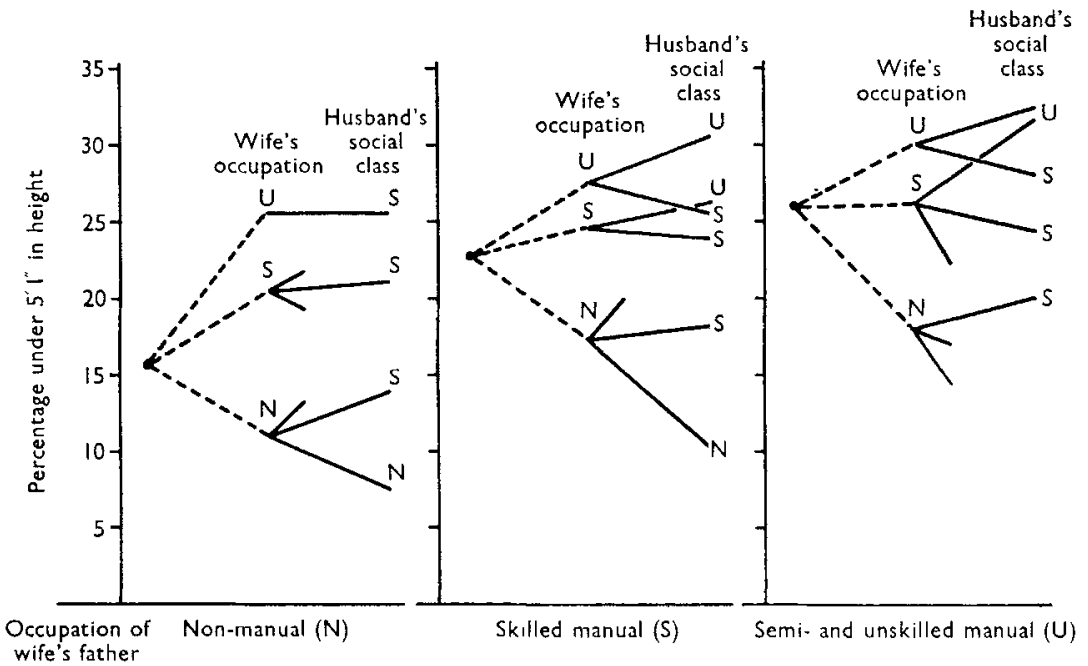

Fig. I. Percentages of wives under $6 \mathrm{I}$ in. in height; 7442 first single maternities in Aberdeen. The three parts of the diagram deal with wives grouped according to the occupations of their fathers. Each main group is then subdivided, first, according to the wife's occupation before marriage, and, second, according to her husband's occupation. In subgroups containing less than 100 subjects the lines are left incomplete. (From Thomson, r959; some errors in the original diagram have been corrected.)

which is undoubtedly largely determined by heredity, and which one would think is seldom of much occupational significance-should be so sensitively associated with occupation. Whether that association is sufficiently explained by the effects upon growth of nutrition and other environmental influences, or whether the socialclass differences also imply differences of innate growth potential, is at present unknown. All we can be sure of is that mean maximum stature in adult populations may change, probably mainly for nutritional reasons (Boyne \& Leitch, I954). It therefore seems reasonable to interpret the social-class gradient in height as at least partly of nutritional origin.

\section{Physique and diet}

Do tall women take better diets than short women? The figures in Table 2, from a survey of Aberdeen primigravidae, show that they do. The tall women were heavier than the short women, and it might be argued that their greater intake of 
calories, and of many nutrients, was simply due to their larger size. But after standardization, by regression, of the calorie intakes to the mean body-weight for all heights tall women still took about $240 \mathrm{kcal} /$ day more than the short women. Many of the differences in the intakes of nutrients are attributable to the differences of calorie intake, but tall women took more calcium and more vitamin $\mathrm{C}$ than could be explained on that basis (Thomson \& Billewicz, 1961).

Table 2. Mean nutritive values of daily diets taken by tall, medium and short primigravidae (from Thomson $\mathfrak{G}^{\circ}$ Billewicz, 196r)

\begin{tabular}{|c|c|c|c|}
\hline & $\begin{array}{c}\text { Tall } \\
(5 \mathrm{ft} 4 \text { in. and over })\end{array}$ & $\frac{\text { Medium }}{(5 \mathrm{ft} I \text { in. }-5 \mathrm{ft} 3 \mathrm{in} .)}$ & $\begin{array}{c}\text { Short } \\
\text { (Under } 5 \mathrm{ft} I \text { in.) }\end{array}$ \\
\hline Calories (kcal) & 2595 & 2475 & 2229 \\
\hline Protein $(\mathrm{g})$ & 80.0 & $75 \cdot 1$ & $69 \cdot 2$ \\
\hline Calcium (g) & $\mathrm{I} \cdot 08$ & 0.99 & 0.85 \\
\hline Thiamine (mg) & $1 \cdot 24$ & I.18 & $x \cdot 08$ \\
\hline Riboflavin (mg) & $\mathrm{I} \cdot 95$ & I. 86 & $x \cdot 67$ \\
\hline Nicotinic acid (mg) & $12 \cdot 1$ & $I I \cdot 7$ & $11 \cdot 0$ \\
\hline Ascorbic acid (mg) & $76 \cdot 5$ & $63 \cdot 8$ & $5^{6 \cdot 9}$ \\
\hline No. of subjects* & 133 & 239 & 117 \\
\hline
\end{tabular}

* Not representing the true distribution by height of the population investigated.

Table 3. Mean nutritive values of daily diets taken by women in three weight-forheight groups. 'Overweight' signifies that the women were in the heaviest $25 \%$ of subjects at each height, and 'underweight' signifies that they were in the lightest $25 \%$. 'Average weight' covers the intermediate 50\% (from Thomson $\mathcal{E}^{\circ}$ Billewicz, I96I)

Calories (kcal)
Protein $(\mathrm{g})$
Calcium $(\mathrm{g})$
Thiamine (mg)
Riboflavin (mg)
Nicotinic acid (mg)
Ascorbic acid (mg)
No. of subjects*
Mean weight at zoth
week of pregnancy $(\mathrm{kg})$
Mean height (cm)

Underweight
$\begin{aligned} & 2400 \\ & 72 \cdot 7 \\ & 0.96 \\ & 1 \cdot 13 \\ & 1 \cdot 83 \\ & 11 \cdot 6 \\ & 68 \cdot 4 \\ & 94 \\ & 49 \cdot 9 \\ & 158.0\end{aligned}$

$\begin{array}{cc}\begin{array}{c}\text { Average } \\ \text { weight }\end{array} & \text { Overweight } \\ 2460 & 2456 \\ 75.4 & 75.5 \\ 0.97 & 0.98 \\ 1 \cdot 19 & 1 \cdot 19 \\ 1.83 & 1.83 \\ 11 \cdot 7 & 11.5 \\ 65.5 & 62.4 \\ 204 & 114 \\ 56.5 & 65.6 \\ 158.2 & 158.5\end{array}$

*The weight-for-height standards were derived from a large representative sample of Aberdeen primigravidae.

Tall women therefore undoubtedly eat more, and on the whole eat better diets than short women, even when differences of body-weight are allowed for. Unexpectedly this is not true when women of different body-weight but of similar height are considered. Table 3 shows the food intakes of the same women when grouped on the basis of weight-for-height. There is almost no difference between the mean intakes, despite a considerable difference of body-weight (Thomson $\&$ Billewicz, I96r). What we found in this group of pregnant women appears to be true of women generally and also of men (Thomson, Billewicz \& Passmore, r96r). Nor, 
in our data, is there any suggestion that obesity or thinness is more common in one social class than another. It may be that, in such a relatively young population, differences in body-weight tend to reflect differences of energy expenditure rather than of energy intake.

To sum up the argument so far: in a population in which frank deficiency disease is absent or rare, the diagnosis of malnutrition is difficult (Thomson \& Duncan, 1954). Differences of nutritional status are undoubtedly associated with differences of general health and development, but clinical impressions of general health and physique, even when based upon a careful examination, are imprecise and sometimes misleading. In these circumstances objective measures of physique may be used with advantage. It should be scarcely necessary to stress that measurements such as height and weight cannot safely be used as the sole indicators of nutritional status in individuals, but should be applied to populations and treated statistically.

Stature may thus be used as a statistic which reflects dietary habits during growth; and since food habits acquired during growth tend to persist, adult stature also tends to reflect nutritional status. Body-weight, which should be standardized for height, may be used as a statistic reflecting the balance between habitual energy expenditure and intake.

\section{Stature and reproductive efficiency}

If these general conclusions are accepted, both height and weight should have some influence upon reproductive efficiency. Tall women, being generally better nourished than short women, should be less liable to suffer disability, and should have babies of higher vitality, than short women. Table 4 shows that it is so. Lest it be objected that the biology of women in Aberdeen is in some way peculiar, we have included also some (unpublished) data from Hong Kong. We have fragmentary information from England and from the USA which also helps to confirm the existence of a positive association between adult stature and reproductive efficiency.

For both the Aberdeen and the Hong Kong (Chinese) women there is evidence of a clear gradient with maternal stature. The shortest women had the highest rates of prematurity, Caesarean section and perinatal death, and the tallest women had the lowest rates. Table 4 shows also that the Chinese women, at any height, had lower rates of all these conditions than the Aberdeen women. The great majority of them came from poor families: but this is not the place to speculate on the reasons for the exceptionally good reproductive efficiency found in Hong Kong.

It is interesting to note that the relatively high incidence of perinatal death in short women is not confined to deaths attributable to difficult labour and birth trauma. The gradient with height persists when the deaths are subdivided into those attributable to birth trauma and those attributable to other causes (Thomson, 1959). It seems evident that the foetus of a short woman has lower vitality and is less likely to be well-grown and to survive than that of a tall woman.

\section{Body-weight and reproductive efficiency}

Since tall women tend to be heavier than short women, it is necessary in the analysis of the effect of weight per se to make allowance for height differences. This 
Table 4. Incidences of prematurity, Caesarean section and perinatal mortality in Aberdeen and in Chinese (Hong Kong) primiparae

\begin{tabular}{|c|c|c|c|c|c|c|}
\hline \multirow[b]{2}{*}{ Height (in.) } & \multicolumn{2}{|c|}{$\begin{array}{c}\text { Prematurity* } \\
(\%)\end{array}$} & \multicolumn{2}{|c|}{$\begin{array}{c}\text { Caesarean section } \\
(\%)\end{array}$} & \multicolumn{2}{|c|}{$\begin{array}{l}\text { Perinatal deaths } \\
\text { per } 1000\end{array}$} \\
\hline & Aberdeen & Hong Kong & Aberdeen & Hong Kong & Aberdeen & Hong Kong \\
\hline Under 57 & 16.3 & $19 \cdot 3$ & $25 \cdot 8$ & 20.5 & 40.7 & $19 \cdot 2$ \\
\hline $\begin{array}{l}57-58 \\
59-60\end{array}$ & 10.3 & $\begin{array}{r}\text { I } 1 \cdot 6 \\
6.6\end{array}$ & I $2 \cdot 5$ & $5 \cdot 0$ & & \\
\hline $\begin{array}{l}59-60 \\
61-62\end{array}$ & $6 \cdot 9$ & $\begin{array}{l}6 \cdot 6 \\
6 \cdot 7\end{array}$ & $\begin{array}{l}5 \cdot 3 \\
3 \cdot 3\end{array}$ & $\begin{array}{l}3 \cdot 1 \\
2 \cdot 3\end{array}$ & $\begin{array}{l}28 \cdot 6 \\
25 \cdot 7\end{array}$ & I $7 \cdot 3$ \\
\hline $63-64$ & $6 \cdot 2$ & & $2 \cdot 7$ & 4.8 & & 14.4 \\
\hline 65 and over & 3.7 & 5.7 & $2 \cdot 4$ & & $2+4$ & \\
\hline
\end{tabular}

has been done by allocating women into weight-for-height groups as described in Table 3. Weight increases during pregnancy, and we have used the weight at the 20 th week as our measure of weight: at that time, weight is on average about $4 \mathrm{~kg}$ greater than weight at conception, most of the increase being due to increased maternal blood volume and body fat (Thomson \& Hytten, I96I).

Table 5 shows the incidence of certain abnormalities in 4215 Aberdeen primigravidae, classified into 'overweight', 'average weight' and 'underweight' groups. The incidence of pre-eclampsia (raised blood pressure and proteinuria, often with some oedema) increases with increase of body-weight, in agreement with the general finding that hypertensive diseases tend to occur most frequently in obese persons. Conversely, the incidence of prematurity (defined as birth weight $2500 \mathrm{~g}$ or less) is greatest in light and lowest in heavy women. In other words, heavy mothers tend to grow heavy babies, a fact which may perhaps reflect an underlying endocrine influence. Not unexpectedly, the overweight women have the highest incidence of delivery by Caesarean section and also a slightly increased perinatal mortality rate. Whether the slightly raised rates of Caesarean section and perinatal death in underweight women are significant is at present doubtful.

Table 5. Incidence of certain abnormalities by weight-for-height in 4215 Aberdeen primigravidae (see Table 3)

\begin{tabular}{|c|c|c|c|}
\hline & Underweight & $\begin{array}{c}\text { Average } \\
\text { weight }\end{array}$ & Overweight \\
\hline Pre-eclampsia $(\%)$ & 4.8 & $6 \cdot 3$ & $8 \cdot 3$ \\
\hline Prematurity* $(\%)$ & $9 \cdot 6$ & $6 \cdot 9$ & $4 \cdot 1$ \\
\hline Caesarean section $(\%)$ & $3 \cdot 7$ & $3 \cdot 0$ & $5 \cdot 8$ \\
\hline Perinatal death $(\%)$ & $2 \cdot 8$ & $2 \cdot 7$ & $3 \cdot I$ \\
\hline No. of subjects & 1049 & 2112 & 1054 \\
\hline
\end{tabular}

\section{Comment}

There is no doubt that differences both of stature and of body-weight are associated with differences of health, assessed in terms of some common reproductive disabilities. So assessed, tall women are, on average, healthier than short women. It seems to be better to be of moderate weight at any given height than to be much 
underweight, and it is particularly undesirable to be overweight. The amount of fat in the body, though no doubt to some extent under endocrine influence, must in practice reflect habits of eating and of activity. Adiposity can be altered in the adult by a suitable regimen, probably with benefit to health. Adult stature, on the other hand, cannot be so altered. If we want to increase the proportion of well-grown and healthy adults in the population, we must improve living conditions and nutrition during growth.

The most important implication of these findings is that it is not sufficient to take care of the diet of women after pregnancy has begun. Nutritional preparation for pregnancy begins in infancy, perhaps even during foetal life.

We thank Professor Daphne Chun, University of Hong Kong, for making available the records from which some of the values in Table 4 were calculated.

\section{REFERENCES}

Bernard, R. M. (1952). Edinb. med. F. 59, Proc. Edinb. obstet. Soc. p. I.

Boyne, A. W. \& Leitch, I. (I954). Nutr. Abstr. Rev. 24, 255.

Thomson, A. M. (1959). Eugen. Rev. 5I, 3.

Thomson, A. M. \& Billewicz, W. Z. (196r). Brit. F. Nutr. 15, 24 I.

Thomson, A. M., Billewicz, W. Z. \& Passmore, R. (I961). Lancet, i, 1027.

Thomson, A. M. \& Duncan, D. L. (1954). Nutr. Abstr. Rev. 24, I.

Thomson, A. M. \& Hytten, F. E. (1961). Proc. Nutr. Soc. 2o, 76.

\section{Some considerations of changes in total body composition in relation to nutritional status}

\section{By H. B. Anstall, Postgraduate Medical School of London, Hammersmith Hospital, London, W.12}

The science of physiology is concerned with the elucidation of the various problems of body function. It comprises many facets, each of them in its own way a speciality, but collectively making up a singularly complex whole. Each of these facets has its own associated techniques, making use of the principles of physics, chemistry, and other sciences. If physiology is to be truly quantitative, means must be devised for the analysis of the body as a whole, i.e. as a living functional unit. Thus there devolves upon us the problem of establishing methods for measuring the magnitude of its various components. For the true understanding of such variations in body composition as occur in nutritional aberrations, it is necessary first to define the normal situation regarding the chemical composition of the body and then to try to find ways of assessing the nature of departures from this state.

Much has been done in the various aspects of this problem. A detailed discussion of the techniques used and the calculation of individual values is beyond the scope of this short communication. What is proposed is to present a short review of the principal methods used for measuring major body components.

The living body is made up of various functional compartments. It is necessary to distinguish between the mainly active components and the mainly inert. Briefly 